\title{
Visões de jogo ${ }^{1}$
}

\author{
Heidi Jancer Ferreira* \\ Roberto Andaki Júnior** \\ José Geraldo do Carmo Salles***
}

\begin{abstract}
Resumo: O livro "Visão de Jogo: antropologia das práticas esportivas", organizado por Luis $\mathrm{H}$. de Toledo e Carlos E. Costa, publicado em 2009, reúne dez capítulos de autores e recortes temáticos diferentes, mas que se entrelaçam na idéia de visão de jogo. O livro não se restringe ao esporte de alto rendimento, ele aborda as práticas esportivas como um todo. Neste contexto são discutidos os domínios de gênero, eficácia simbólica, sociabilidade, política e ethos dos jogadores brasileiros.
\end{abstract}

Palavras-chave: Esportes. Jogos e brinquedos. Antropologia.

Os esportes, especialmente o futebol, são práticas corporais massificadas dentro da cultura nacional e estão presentes nos distintos cantos do país em suas várias modalidades. As práticas esportivas representam manifestações de coletividade, sociabilidade entre indivíduos, identidade, sentimentos de competição e rivalidade, entre outros aspectos constitutivos de sistemas simbólicos que estão imbricados no movimento corporal e na realização do jogo em si. Esses aspectos podem ser interpretados para melhor compreensão de uma cultura, constituindo assim, campo fecundo para a pesquisa antropológica.

\footnotetext{
${ }^{1}$ Essa resenha foi realizada como proposta da disciplina Antropologia Social, coordenada pela Prof ${ }^{a}$. Dra. Sheila Maria Doula, do Programa de Pós-Graduação em Extensão Rural da Universidade Federal de Viçosa.

*Departamento de Educação Física. Universidade Federal de Viçosa (UFV), Minas Gerais, Brasil. E-mail: hfjancer@yahoo.com.br

**Departamento de Educação Física. UFV. Viçosa, MG, Brasil. E-mail: robertoandakijr@gmail.com ***Departamento de Educação Física. UFV. Viçosa, MG, Brasil. E-mail: gege_handebol@yahoo.com.br
} 
O livro "Visão de Jogo: antropologia das práticas esportivas" foi organizado por Luiz Henrique de Toledo e Carlos Eduardo Costa. Toledo é doutor em Antropologia Social pela USP, professor e coordenador do Programa de Pós-Graduação em Antropologia Social na Universidade Federal de São Carlos (PPGAS-UFSCar). Ele desenvolveu em sua trajetória acadêmica estudos sobre torcidas organizadas de futebol e dimensões simbólicas no futebol. Também publicou os títulos Torcidas organizadas de futebol (TOLEDO, 1996), No país do futebol (TOLEDO, 2000) e Lógicas no futebol (TOLEDO, 2002). Costa é aluno de doutorado do PPGAS-UFSCar e desenvolve pesquisa junto aos índios Kalapalo com o intuito de debater as atividades esportivas praticadas por eles.

Esse título reúne estudos de vários autores com diferentes níveis de formação dentro da área das Ciências Sociais e da Antropologia Social. São quatro textos oriundos de trabalhos de iniciação científica dos mestrandos Júlio Palmiéri, Juliana Coelho e Lara Stahlberg e do mestre Leonardo Oliveira; quatro são frutos de dissertações de mestrado de Claudemir Santos e dos atuais doutorandos Carlos Costa, Thiago Oliveira e Sandro Franciscchini; e, um é decorrente da pesquisa de pós-doutorado de Reinaldo Aguiar. Essa publicação é resultado de um projeto de pesquisa, ao qual estiveram vinculados a maioria dos trabalhos citados. O projeto "Das formas simbólicas e natureza social dos esportes coletivos: perspectiva comparada em antropologia do esporte" foi desenvolvido entre os anos de 2005 e 2009, sob supervisão de Toledo.

O objetivo da obra é apresentar a "visão de jogo" dos autores produzida a partir da experiência vivida por cada um, ou seja, apresentar aos leitores a interpretação tecida por eles sobre os aspectos simbólicos presentes nas práticas esportivas e que são compreendidos apenas pelos seus participantes: torcedores, profissionais e especialistas.

O livro é composto por dez capítulos que abordam diferentes recortes temáticos no campo das práticas esportivas. Na coletânea, 
os autores se embasam na literatura de autores clássicos e contemporâneos da Antropologia, Antropologia do Esporte, Sociologia e Sociologia do Esporte.

O primeiro capítulo, Torneios universitários: disputas e sociabilidade nas práticas esportivas estudantis, de Carlos Eduardo Costa, busca expandir para os torneios universitários o modelo das formas-representações, proposto por Toledo em relação ao futebol. O texto elucida que os torneios universitários são mais que competições esportivas, uma vez que em torno deles são criadas representações de sociabilidade, decorrentes da estreita relação presente nesses eventos entre esporte e festa. As práticas esportivas são entendidas de forma diferenciada no ambiente universitário, pois elas se dão através de diversas formas de jogar que mesclam a rivalidade esportiva com a diversão das festas.

O segundo capítulo, A sociabilidade esportiva das igrejas Renascer em Cristo e Bola de Neve, de autoria de Reinaldo Olécio Aguiar, analisa a sociabilidade esportiva em duas igrejas neopentecostais. $\mathrm{O}$ autor considera a expressão corporal e a dança rítmica dos corpos nos cultos com objetivo de adoração e louvor como a esportivização do sagrado.

Juliana Affonso Gomes Coelho, em seu texto intitulado Voleibol: um espaço híbrido de sociabilidade esportiva, utiliza a categoria de gênero baseada na definição de Scott para demonstrar que o voleibol pode ser compreendido como um espaço híbrido que engloba tanto homens como mulheres em sua prática. A autora infere que essa hibridização pode ser justificada pelo fato do voleibol, um esporte originalmente masculino, ter sido apropriado pelas mulheres ao longo de sua evolução. O capítulo evidencia como o voleibol permite a aquisição de identidades contrastantes, bem como a contestação e a afirmação simultâneas dos discursos dominantes de masculinidade e feminilidade.

Julio César Jatobá Palmiéri em seu texto Futebol e basquete made in Brazil: uma análise antropológica do fluxo de jogadores 
para o exterior estabelece uma comparação entre o fluxo de jogadores brasileiros para o exterior entre o basquete e o futebol. Esse capítulo aponta como o estilo de jogo praticado nos países estrangeiros e as trocas culturais refletem e acabam influenciando nas formas de jogar dos brasileiros.

O capítulo Voleibol no interior: um estudo de caso sobre o ethos dos jogadores, de Leonardo Erivelto Soares de Oliveira, apresenta uma análise sobre a existência de um estilo de "jogar à brasileira" no voleibol. Após traçar a história e a evolução das regras da modalidade e relatar a sua experiência vivida junto ao cotidiano de treinamento de duas equipes paulistas, o autor levanta a hipótese de que permanece uma representação no imaginário brasileiro sobre a criatividade como principal característica que acaba influenciando na construção do estilo de jogar voleibol no Brasil.

Jogando em vários campos: torcedoras, futebol e gênero de autoria de Lara Tejada Stahlberg também com um enfoque sobre gênero, discute o espaço das mulheres nas torcidas de futebol. $\mathrm{O}$ texto analisa como a dominação masculina no futebol, a rotulação e a diferenciação dos olhares "de fora" e "de dentro", ou seja, de quem não pratica e de quem pratica a modalidade geram implicações na legitimidade da visão de jogo das mulheres. Desde suas primeiras manifestações, as práticas esportivas são marcadas pela dominação masculina, uma vez que os esportes foram criados pelos homens e para os homens, constituindo até os dias atuais como campo de entraves e tensões entre o masculino e o feminino.

Sandro Francischini em A difícil nacionalização do futebol brasileiro: a era Havelange revela a lógica política tão presente e decisiva nos rumos da organização esportiva do Campeonato Brasileiro de Futebol. Evidencia também como a figura de João Havelange pode ter representado as alianças e negociações entre o mundo do futebol e da política.

No capítulo Deus e o diabo na terra do futebol: reflexões sobre a disputa totêmica América Football Club, Thiago Passos de Oliveira discute a representação simbólica, os valores religiosos 
e o imaginário social na disputa entre torcedores, dirigentes e profissionais do futebol vinculados ao América Futebol Clube sobre o uso e a apropriação de dois símbolos que, em determinado tempo, representaram o time: o diabo e a águia.

No Brasil, fala-se muito que o brasileiro já nasce com o futebol nos pés, considerando a habilidade esportiva como um talento inato. Existe mesmo esse "jeitinho brasileiro" para praticar esportes? O capítulo de Claudemir José dos Santos, Repensando o estilo à brasileira: escolinhas de futebol e aprendizagem esportiva aponta que existe sim uma característica marcante nos jogadores brasileiros: a criatividade. No entanto, o fator determinante é a aprendizagem de habilidades motoras. Seja na rua ou em escolinhas, a quantidade de vivência e de experiência lúdica da criança é o que a conduz a um alto nível de habilidade e criatividade no esporte.

No último capítulo, Estilos de jogar, estilos de pensar: esboço comparativo entre Damatta e Archetti, Luiz Henrique Toledo apresenta uma comparação entre os estilos de fazer antropologia do esporte de DaMatta e Archetti, ressaltando as marcas de cada autor.

Os capítulos desenvolvem temas diferentes, mas que se entrelaçam e se comunicam em um horizonte, o do significado da expressão "visão de jogo", evidenciando que existem várias formas e sentidos que podem ser atribuídos ao jogo, conforme os diferentes contextos e agentes envolvidos na prática. Dependendo da forma e do campo de visão, é possível obter várias visões de jogo, o que, nas palavras de Toledo e Costa,

[...] seria imprimir uma qualidade aos fatos, seria produzir outra versão sobre o acontecimento, distinguir-se, ou ter a possibilidade de ler uma narrativa em grande parte exuberante, porque corporal, na chave de outros recursos discursivos e simbólicos. (TOLEDO; COSTA, 2009, p. 14)

O "ver" é uma forma importante de participar das práticas esportivas, assim como o "jogar", o que legitima a voz não apenas de jogadores, treinadores e praticantes em geral, mas também dos torcedores e dos especialistas que falam sobre os esportes, que 
opinam, explicam, reclamam e elogiam. Os expectadores fazem parte do jogo e do espetáculo, influenciando a prática em si pelo simples fato de estarem observando. Os torcedores experimentam uma catarse como se estivessem em campo ou em quadra, como os verdadeiros jogadores. Portanto, no esporte, jogadores e torcedores jogam juntos, fazendo com que a visão de jogo possa surgir tanto de uns como de outros. No livro, os organizadores buscaram envolver esses vários agentes atuantes nas práticas esportivas.

Além da definição central de "visão de jogo", os organizadores optaram adequadamente por delimitar a obra como uma antropologia das práticas esportivas ao invés de antropologia dos esportes. A escolha é justificada pelo fato de que a antropologia dos esportes se remete e se restringe a modalidades esportivas de alto nível, regulamentadas e reconhecidas internacionalmente, os esportes propriamente ditos. Por sua vez, a antropologia das práticas esportivas amplia seu olhar para outras práticas corporais, performances, representações lúdicas e competitivas que podem ser ressignificadas conforme o local onde são praticadas e os sentidos atribuídos por seus praticantes.

Os autores se utilizaram da etnografia como procedimento metodológico para revelar os aspectos simbólicos existentes nas práticas esportivas, enfatizando o "ver/olhar" para o objeto como exercício fundamental para realizar o trabalho antropológico. A maior parte dos capítulos, portanto, baseia-se nos pressupostos teóricometodológicos clássicos da Antropologia. Porém, o texto de Francischini não está alinhado com esses pressupostos, uma vez que não empregou a etnografia como método de pesquisa, o que era elemento de integração dos textos e de articulação com a proposta da obra. Por se tratar de um trabalho de narrativa histórica, esse capítulo nos pareceu dissonante do livro, já que foi delimitado como antropologia das práticas esportivas. Entretanto, Francischini fez um texto rico sobre a história e as tensões políticas presentes no futebol brasileiro nos anos 70 . O recorte temático é bastante relevante por se referir a um período que foi marcante para a modalidade por quatro motivos: o Brasil foi Tricampeão mundial de futebol; houve a massificação da construção de estádios por iniciativas 
governamentais; João Havelange foi eleito como presidente da FIFA em 1974; e, ocorreu a implantação do Campeonato Brasileiro de Futebol em 1979.

Uma novidade aparece na metodologia dos trabalhos de Costa e Stahlberg, quando apresentam o Orkut, um site de relacionamento na internet, como campo para coleta de dados para pesquisas antropológicas. Opção esta, que é justificada pela grande participação e envolvimento das pessoas em ambientes virtuais, onde trocam informações, argumentam em fóruns, se identificam em "comunidades" e falam o que querem sobre tópicos relativos aos esportes.

O livro afirma e expande o conceito de "formas-representações" proposto por Toledo (2002) em outra obra. Esse conceito baseia-se no pressuposto de que numa prática esportiva estariam dispostos três tipos de natureza: regras, formas e representações. As regras constituem a estrutura rígida da modalidade esportiva, na qual vão se enquadrar as formas; estas consistem nas disposições e performances previamente estabelecidas e treinadas, como os esquemas táticos; e, por último, as representações se encontram numa dimensão simbólica, codificando as formas e caracterizando os estilos de jogo.

No livro faz-se necessário esclarecer qual a definição adotada para algumas noções. Na apresentação, Toledo e Costa informam que optaram pela expressão "práticas esportivas" para ganharem mais mobilidade temática e não se limitarem a discutir apenas antropologia de esportes de alto nível. Entendemos que essa escolha foi bem prudente e eximiu a obra de entrar na discussão sobre o conceito "esporte". No entanto, essa pretendida mobilidade afrouxouse demasiadamente no segundo capítulo ao retratar a riqueza de gestos e os movimentos coreografados realizados em cultos de igrejas neopentescostais como uma prática esportiva. Os movimentos rítmicos foram incorporados pelos religiosos como forma de despertar emocional e de ligação com o sagrado, diferentemente das práticas esportivas. Ainda que a linguagem corporal utilizada nos cultos tenha um caráter socializador e de catarse como também ocorre nos 
esportes, ela não pode ser considerada como tal. Existe sim uma aproximação entre religião e esportes, entretanto essa relação não permite configurar as práticas corporais adotadas na religião como práticas esportivas. Aguiar fez um trabalho rico sobre o movimento nos cultos religiosos, entretanto seu texto não conseguiu se relacionar com os demais e nos pareceu deslocado dentro da coletânea. O capítulo foge à proposta do livro e não cumpre com as expectativas geradas pelo próprio título. O conceito anunciado no título de "sociabilidade esportiva" não se encontra bem arranjado e não se encaixa com a discussão que foi desenvolvida no trabalho. Aguiar entende "sociabilidade esportiva" como a religião em ação através dos cânticos e das danças rítmicas dos corpos, o que nos parece inadequado. A nosso ver, a opção pelos termos não foi apropriada. Possivelmente, noções mais abrangentes, como técnicas corporais de Marcel Mauss (1974) e sociabilidade, de uma forma geral, fossem mais adequadas para tratar da temática das práticas corporais nas manifestações religiosas.

No campo de estudo da antropologia dos esportes, "Visão de jogo: antropologia das práticas esportivas" vem contribuir para a expansão do conhecimento nessa área de estudo e ampliação do leque para a discussão de práticas esportivas, que, muitas vezes, se limita às fronteiras do futebol. A leitura da obra, de fácil compreensão, se torna relevante principalmente para jovens pesquisadores na área da Educação Física, Ciências Sociais e Antropologia, possibilitando a compreensão de fatos, sentidos e significados ocultos em diversos tipos de práticas esportivas, com embasamento e diálogo teórico.

É importante ressaltar que apesar de todos os recortes dos objetos de pesquisa se referirem ao estado de São Paulo, é possível olhar para eles e para suas explicações e aplicá-las em outras realidades, outras subculturas e locais diferentes. O alcance dessa possibilidade é de suma importância e reafirma a obra dentro dos propósitos de trabalhos antropológicos, como o de permitir um "jogo de espelhos" entre várias culturas. 


\section{Views of game}

Abstract: The book entitled Visão de Jogo: antropologia das práticas esportivas ("View of game: an anthropology of sports practice") by Luis $\mathrm{H}$. de Toledo and Carlos E. Costa, published in 2009, brings ten chapters and surveys of different aspects of sports, although they intertwine in the conception of view of game. Beyond high performance sports, Toledo and Costa approach sports practice in its totality. In that context, they discuss gender relations, symbolic effectiveness, sociability, politics, and Brazilian players' ethos.

Keywords: Sports. Play and playthings. Anthropology.

\section{Visiones de juego}

Resumen: El libro Visão de Jogo: antropologia das práticas esportivas ("Visión de juego: antropología de las prácticas deportivas"), organizado por Luis $\mathrm{H}$. de Toledo y Carlos E. Costa, publicado en el año 2009. La obra reúne diez capítulos de autores y recortes temáticos diferentes, que se entrelazan en la idea del juego. El libro, no sólo se limita al deporte de alto rendimiento, sino que aborda las prácticas deportivas como un todo. En éste contexto son discutidos los dominios de género, eficacia simbólica, social, política y ethos de los jugadores brasileños.

Palabras-clave: Deportes. Juegos y implementos de juego. Antropología. 


\section{REFERÊNCIAS}

MAUSS, Marcel. As técnicas corporais. In: MAUSS, M. Sociologia e antropologia, São Paulo, v. 2, p. 209-234, 1974.

TOLEDO, Luiz Henrique de. No país do futebol. Rio de Janeiro: Zahar, 2000. Lógicas no futebol. São Paulo: Hucitec/Fapesp, 2002.

Torcidas organizadas de futebol. Campinas: ANPOCS, Autores Associados, 1996.

TOLEDO, Luiz Henrique de; COSTA, Carlos Eduardo (Org.). Visão de jogo: antropologia das práticas esportivas. São Paulo: Terceiro Nome, 2009.

Endereço para correspondência:

Heidi Jancer Ferreira

Rua Dos Estudantes, № 90 apt 32

Centro - Viçosa- MG

CEP 36570-000

Recebido em: 10.08.2010

Aprovado em: 24.03.2011

Movimento, Porto Alegre, v. 17, n. 02, p. 281-290, abr/jun de 2011. 
